\title{
Inspirational Women in Surgery: Dr. Olive Kobusingye, Uganda
}

\author{
Charles Mock ${ }^{1}$
}

Accepted: 27 November 2021 / Published online: 5 January 2022

(C) The Author(s) under exclusive licence to Société Internationale de Chirurgie 2021

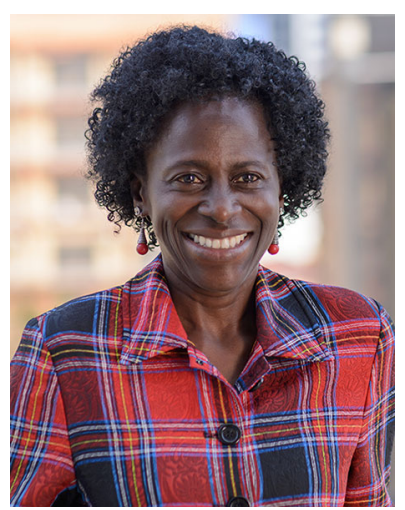

Dr. Olive Kobusingye has spent her career taking on an enormous challenge-improving trauma care in Uganda, in Africa, and worldwide. She was born in a village in southwestern Uganda, $5^{\text {th }}$ in a family of six children. Her mother was a teacher and her father was a policeman and later a trader in agricultural produce. Both of her parents died young - her father when she was five and her mother when she was eleven. She went to all-girls missionary boarding schools until university. Her first ambition was to be an engineer, but she was talked out of it by her elder brother who was then at medical school. He told her that at Makerere University women did not do well in engineering no matter how bright they were. Medicine was her second choice.

Once at Makerere, she at first thought of going into forensic pathology and then psychiatry, but neither really caught her attention. Surgery was different. She saw patients brought in half dead and revived within a few

Charles Mock

cmock@uw.edu

1 Surgery, University of Washington, Seattle, USA hours of intervention. Her five years at medical school coincided with the five years that the National Resistance Army fought a civil war that left more than half a million Ugandans dead. She saw many victims of the war during her training. She did a rotating internship at Machakos General Hospital, in Kenya, to experience medicine in a more stable environment. It was here that she decided to pursue a career in surgery. Dr. Mohamad Alkama was head of surgery, and it was a joy to scrub for him. His operating lists included a great variety of surgeries, ranging from neurosurgery, orthopedics, general surgery and pediatric surgery. He did all of them with a positive attitude, always giving interns opportunities for hands-on experience during the surgery.

Two years later she returned to Uganda to begin her surgical residency and found that medical services were still quite poor. Shortages were a constant frustrationshortage of almost everything-sutures, equipment, anaesthesia, medicines, lab reagents. To compound the problem, AIDS was ravaging the country, putting medical workers at great risk. But, she felt herself very fortunate to have excellent surgeons as her teachers, especially Prof. JC Ssali who was her immediate supervisor, and who turned out to be a quieter, older version of Dr. Alkama.

Later when she decided to focus on accident \& emergency surgery, the shortages did not let up, yet her patients could not wait for relatives to go and sell household property to buy medical supplies. The cost of mismanaged medical services in terms of lives needlessly lost was always "in her face"- especially the year she spent as the Acting Head of the Accident \& Emergency at Mulago Hospital, the main hospital in the country. Frustrated at the many needless injuries, especially from road traffic crashes, she decided to take on trauma care and injury prevention as the focus of her career. 
Over the ensuing two decades, she has been a major force in promoting both trauma care and injury prevention in low- and middle-income countries (LMICs) globally. She founded the Injury Prevention Center at Makere University, one of the first academic injury prevention centers in Africa. Her research addressed straightforward ways to improve care for the injured in LMICs, something that she realized was possible, despite the extreme resource limitations. A major scientific contribution was her development of the Kampala Trauma Score (KTS), a simple way to risk-adjust injured patients, especially in locations where it would be difficult and time consuming to use the more complex scales used in high-income countries. The KTS is now used around the world. She also co-developed a training course for teams working in emergency units-the Trauma Team Training course. She has looked for ways to improve trauma care broadly in many countries, spending 5 years as the WHO Regional Adviser on Injury for Africa, based in Brazzaville, Congo, providing input on trauma care to 46 African countries.

She has always had an ability to see beyond the immediate problems, to the bigger issues that hamper care in places like Uganda. She states: "In trauma, patients are still getting debilitating osteomyelitis because there is not enough saline to do a decent debridement. Patients are dying for lack of a chest tube. These problems are not for 'the surgical community' to resolve. They are political problems. Perhaps the surgical community needs to begin addressing upstream factors which make our practice of surgery an impossible task." This has led her to write two books addressing such bigger factors, in medical care overall and in politics $[1,2]$.

Despite the numerous frustrations in her work, she maintains a hopeful outlook. "I did not foresee it back then, but the thing I am most proud of now is having spent time with students. Having taken the time to show younger doctors how to do procedures that truly mattered to patients' recovery. Even with severe shortages, there is always something we can offer patients. Good listening and a thorough exam. Gadgets are great, and if one has them, they should definitely use them to the max, but nothing seems to be able to replace good clinical acumen yet."

\section{References}

1. Kobusingye O. The Correct Line?: Uganda Under Museveni. AuthorHouse, UK, Central Milton Keynes, UK, 2010, ISBN: 978-1-4520-3962-6

2. Kobusingye O. The Patient: Sacrifice, Genius, and Greed in Uganda's Healthcare System. AuthorHouse UK, Bloomington, IN, USA, 2020, ISBN: 978-1-7283-9585-2

Publisher's Note Springer Nature remains neutral with regard to jurisdictional claims in published maps and institutional affiliations. 